\title{
Arte público entre la combinatoria relacional y el arte como pasión inapropiada
}

\section{Public art between relational combinatorial and art as inappropriate passion}

\author{
JAVIER MAÑERO-RoDicio \\ CES Felipe II, Universidad Complutense de Madrid. \\ javier.manero@ajz.ucm.es
}

Recibido: 30 de abril de 2012

Aprobado: 1 de junio de 2012

\section{Resumen}

Existe consenso acerca de que, si puede hablarse de un Arte público -que no meramente para espacios públicos-, sería un arte siempre orientado a la esfera social y a una recepción compartida. Expresamente o no, su texto sería entonces político. Pero en las dos últimas décadas es el arte en su conjunto quien piensa la recepción y asume su inevitable dimensión pública, generando así debates acerca de su proyección social y emancipadora. Este estudio se traza desde una parte de la teoría surgida en tal sentido, teoría particularmente relevante para pensar qué pueda ser un Arte público hoy. Desde la idea de un límite expandido como diversidad emancipadora y a través del concepto de intersticio social, se presenta ampliamente la estética relacional y el concepto de posproducción, poniendo de relieve en la discusión el exceso formal-comunicativo de su teoría y el peligro de disolver los contenidos en mera fenomenología relacional. Dando por descontado el interés que la práctica relacional tiene para un Arte público, pero también su discutible alcance político, se reflexiona finalmente acerca del inevitable ser político del arte, señalando, en un giro ilustrado, que es preferentemente desde una acción estética cómo este puede hacerse efectivo en la esfera social.

Palabras clave: Arte público, Tercer paisaje, Intersticio social, Estética relacional, Arte político.

Mañero-Rodicio, J. (2013): Arte público entre la combinatoria relacional y el arte como pasión inapropiada. Arte, Individuo y Sociedad, 25(2) 289-302

\begin{abstract}
There exists a consensus about the fact that, if there is such thing as public art - not just art for public spaces, it would always be an art that is focused on the social sphere and on a shared reception. Expressly or not, its text would therefore be public. But during the last two decades it is art as a whole that is thinking about reception and recognizing its unavoidable public dimension, thus generating debates around it social and emancipatory dimensions. This text stems from a part of the theory appeared in that sense and particularly relevant in thinking what Public Art can be today. From the idea of an expanded limit as emancipatory diversity and through the concept of social interstice, relational aesthetics and the concept of postproduction are thoroughly presented, underlining in the conversation the formal-communicative excess of its theory and the danger of diluting the contents into mere relational phenomenology. Taking for granted Public Art's interest in relational aesthetics, but also its debatable political potential, there is a final reflection about the inevitable political being of art, pinpointing, in an illustrated bend, that it is preferably from an aesthetic action that it can become effective in the social sphere.
\end{abstract}

Key Words: Public art, Third landscape, Social interstice, Relational aesthetics, Political art.

Mañero-Rodicio, J. (2013): Public art between relational combinatorial and art as inappropriate passion. Arte, Individuo y Sociedad, 25(2) 289-302 
Sumario: 1. Introducción. Para un arte público. 2. Paisaje y margen. Poética del Tercer paisaje. 3. Arte, público, producción. Estética relacional y posproducción. 4. Distanciamiento estético y disenso político. Referencias.

\section{Introducción. Para un arte público}

En una concentrada categorización, Peter Bürger atribuye a tres tipos de arte -el sacro, el cortesano y el burgués- sendos modos de producción y recepción. El sacro se produciría artesana-colectivamente siendo también colectiva su recepción; el cortesano se debería a productores individuales mientras que su recepción sería colectiva; en cuanto al burgués, el arte europeo desde la Ilustración, se caracterizaría por una producción y por una recepción igualmente individuales. La autonomía a la que desde el siglo XVIII aspira ese arte burgués, que culmina en los esteticismos modernos de comienzos del s. XX (les modernismes), se dirige exclusivamente a un espectador individual obviando entre ambos -obra y receptor- cualquier otro contenido que no sea el propio arte. Su praxis autónoma deviene inevitablemente institucional (institución arte) y ajena a la praxis vital de los receptores a la que, sin embargo, sí se atenía el arte sacro y el cortesano. Las vanguardias históricas -según Bürger: Dadá, Surrealismo y Constructivismo productivista- habrían procedido a desestabilizar tal autonomía y su correlato, la institución arte, pero recuperando dialécticamente ese momento autónomo del arte para la praxis vital y lanzándolo a una recepción nuevamente colectiva, es decir, a la esfera social (Bürger, 2000). Se trata de un análisis ya clásico que determinó pronunciamientos muy diversos en la crítica posmodernista y que sirve aquí para introducir de un modo complejo las nociones que, en relación a la de Arte público, motivan este escrito: intersticio, recepción relacional y política. Lo hace de un modo complejo porque el proyecto vanguardista resta inevitablemente inconcluso y la tensión del arte entre lo instituido y lo vital se mantiene hoy en un bucle permanente.

Un bucle en el que conviven posibilidades artísticas muy desigualmente dirigidas hacia esa recepción colectiva que ha sido lo propio del arte a lo largo de casi toda su historia. Indudablemente, la noción de Arte público -asumiendo desde este momento su laxo significado y lo indefinido de sus límites- se integraría preferentemente en este ámbito inserto en la esfera social, y ello, bien desde un carácter más autónomo e implicado en poéticas y estéticas personales, pero que se abren al ámbito de lo publico; o bien desde un compromiso más expresamente social, crítico y actuante. En ambos casos, abrirse a lo público implicará lo político aunque, ciertamente, habría que decidir primero qué es lo político, como más adelante se ensayará, para después sopesar si una propuesta artística, de arte público o no, actúa políticamente. Tal vez hallemos que no son los aspectos más expresamente políticos de una obra lo que confiere a esta su capacidad de reactivar nuevos vínculos intersubjetivos, puede que obras ajenas a las alegorías políticas tengan, sin embargo, ese potencial actuante y ello desde una clase de acción alternativa como es la estética.

Este es el punto que interesa dilucidar en este momento: cómo el arte pueda hoy, desde un irrenunciable grado de autonomía, mantener tal como solicita Adorno un estatus negativo para devenir socialmente actuante, político en definitiva, pero 
desde una acción estética que no naufrague ni en los torbellinos relacionales, ni en la univocidad de significados. A continuación y al hilo de algunos autores y textos que aportan discursos de referencia sobre estas cuestiones, se identifican algunas nociones estéticas y críticas que proporcionan interesantes argumentos para construir una idea actualizada de lo público y lo político en el arte. Nociones que, aunque no específicas del ámbito del arte público, se le pueden aplicar íntegramente y que se van a desarrollar bajo los siguientes epígrafes: -Paisaje y margen. Poética del Tercer paisaje. -Arte, público, producción. Estética relacional y posproducción. -Distanciamiento estético y disenso político.

\section{Paisaje y margen. Poética del Tercer paisaje}

La modernidad ilustrada fue indudablemente un proyecto de emancipación. Pero, tal como ha sido ampliamente discutido, su insistencia en la razón y en su leitmotiv, el progreso, limitó y trastocó hasta la nausea las que habrían sido sus justas expectativas. Lo marginal y no centrado no encuentra acomodo en él, sería un mal, un defecto en el esquema darwiniano que las lecturas instrumentales de lo moderno han impuesto y aún mantienen. Los resquicios, los intersticios, hay que sellarlos, pues en ellos crecen plantas cuyas raíces deterioran la construcción de lo útil, se forma hielo que resquebraja la confianza como advenimiento de la entropía.

Nicolas Bourriaud, cuya teoría relacional se abordará después, ilustra con nociones extraídas de Marx su idea de "la obra de arte como intersticio social" (2008), como práctica de resistencia desde el propio tejido social. Efectivamente, Marx utilizó el concepto de "intersticio" para designar aquellas prácticas de intercambio no asimilables en el marco de un comercio basado en la ganancia: el trueque, por ejemplo, pero también la producción autónoma y otras formulas económicas. Son formas de relación ajenas al intercambio capitalista aunque no necesariamente antagónicas e incompatibles con él. Sustituyamos ahora "capital" por "industria cultural", un término acuñado por la Teoría crítica para expresar la instrumentalización de la cultura que, despojada de su valor de uso, deviene mercancía (Adorno \& Horkheimer, 2007). Podemos, a continuación, profundizar en esta analogía equiparando el trueque o la autarquía -los intersticios de Marx- con lo que pudiera ser una cultura en el margen, una cultura emancipadora respecto al continuo de la industria cultural. El arte pertenecería a este campo límite, sería en sí mismo una discontinuidad, un intersticio, un disenso. Su valor es de uso. Lo que no impide que la omnímoda industria cultural instituya su lugar simbólico y le otorgue un valor de cambio.

Habitar los límites (Fig. 1). "Considerar los límites como un grosor y no como un trazo" (2007), tal como aconseja uno de los aforismos de Gilles Clément en su Manifiesto del Tercer paisaje. La extensión de agua de una presa hidroeléctrica, así como los frondosos bosques salpicados de verdes prados que la bordean, se nos presenta como cosa natural. Pero nuestro paisaje, árboles y hierba, es fruto de una economía selectiva cuya consecuencia inmediata o histórica es la limitación progresiva de la diversidad. Quedan, sin embargo, en nuestros paisajes occidentales, "espacios indecisos, desprovistos de función" en los que no solemos reparar: 
Este conjunto no pertenece ni al dominio de la sombra ni al de la luz. Está situado en sus márgenes: en las orillas de los bosques, a lo largo de las carreteras y de los ríos, en los rincones más olvidados de la cultura, alli donde las máquinas no pueden llegar. Cubre superficies de dimensiones modestas, tan dispersas como las esquinas perdidas de un prado. Son unitarios y vastos como las turberas, las landas y ciertos terrenos yermos surgidos de un desprendimiento reciente. Entre estos fragmentos de paisaje no existe ninguna similitud de forma. Solo tienen una cosa en común: todos ellos constituyen un territorio para la diversidad. En todas las demás partes ha sido expulsada. Este hecho justifica que los reunamos bajo una sola expresión. Propongo Tercer paisaje.

Tercer paisaje remite a tercer estado (no a tercer mundo). Es un espacio que no expresa ni el poder ni la sumisión al poder. Se refiere al panfleto de Sieyes de 1789: “QQué es el tercer estado? Todo. ¿Qué ha hecho hasta ahora? Nada. ¿Qué aspira a ser? Algo.” (Clément, 2007, p. 4).

La intensidad metafórica de este tercer paisaje de Clément se reconoce fácilmente en muchas aspiraciones sociales y culturales cuyo imaginario no expresa, efectivamente, ni el poder ni la sumisión al poder. Son nociones estrictamente paisajísticas y ecológicas que, sin embargo, participan del aire de los tiempos y coinciden con muchas de las ideas que han conformado el debate artístico de las dos últimas décadas. Ideas que, desde diversas ópticas, inciden en que el arte, sea desde la acción estética, sea desde la acción relacional, o bien desde la acción crítica, tiene su campo de actuación efectivo en/o a través de los "terceros paisajes" de nuestros entornos y sociedades.

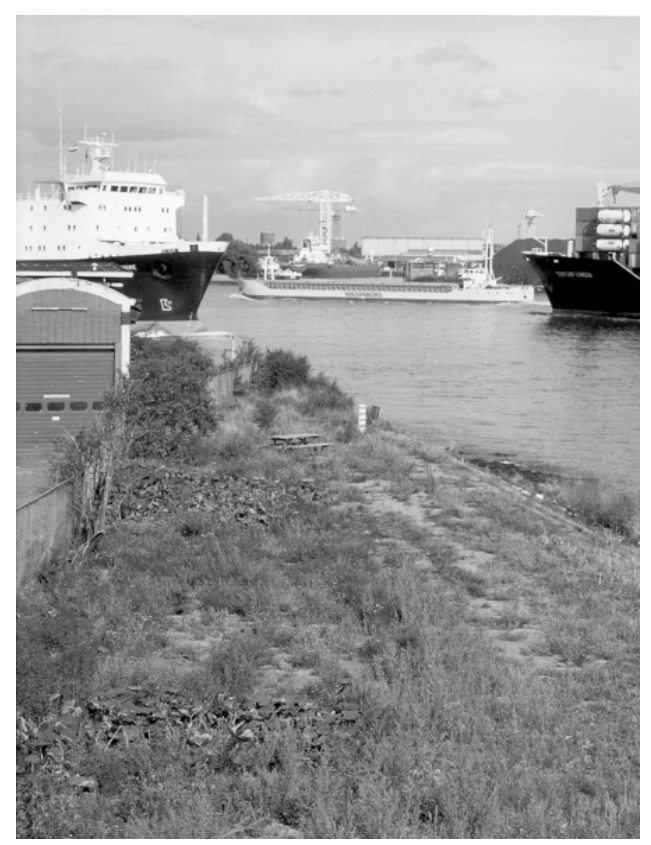

Figura 1. Lara Almarcegui, Un descampado en el puerto de Rotterdam, (Concesión desde 2003 hasta 2018) Rotterdam 2003. 
Pero estos paisajes de los lindes, del límite expandido, tan poéticamente expresados, son perfectamente reales y quieren ser observados no como válvula de escape o término esteticista; sino como elemento de presión, como las raíces o el hielo empujando, formaciones capaces de generar a su vez nuevas manifestaciones del tercer paisaje, nuevas desgarraduras de la cultura y la política donde, no ya lo público, entelequia demasiado abstracta y monolítica, sino lo detalladamente colectivo y lo socialmente individual halla nuevos acomodos. Son paisajes reales en el sentido de que sirven para desvelar algún que otro simulacro, para recuperar, aunque fragmentariamente, aspectos del mundo no planificados, para recuperar la diversidad y la atención más allá de la escena útil a la lógica globalizadora. Se definen, pues, como reservas de diversidad y en consecuencia como pervivencia o posibilidad de un proyecto emancipador. Efectivamente, la anterior alusión al Tercer estado hace explícita la estela ilustrada que recorre este Manifiesto del Tercer paisaje, una herencia que el pensamiento europeo nunca ha obviado ni siquiera en los desvaríos más nihilistas de la posmodemidad. Pero se trata de una Ilustración que expresa su moderado afán revolucionario, su renuencia a la ideología fuerte, en ese modesto aspirar a "ser algo" aun a sabiendas de que el Tercer estado es por naturaleza todo.

Traer estas antiguas nociones a la actualidad implica, al mismo tiempo, una recuperación de ideales al fin y al cabo modernos, y una aceptación fáctica de la situación: un reconocimiento de que, como afirma el artista Liam Gillick, somos prisioneros del escenario del capitalismo tardío. El trabajo del arte tendría que ver con desentrañar los mecanismos de ese escenario -y tal ha sido el objetivo del posmodernismo crítico- pero también con generar contra-escenas a modo de cuadros disonantes que, actuando dentro del escenario colectivo (Bourriaud, 2009), incluso tomando de él sus materiales, cree otros relatos. En realidad, lo mejor y lo peor de una resistencia de esta clase, del intersticio, del tercer paisaje, o de la recuperación micropolítica del proyecto emancipador, es que no hay otra utopía que la de reinstaurar espacios de diversidad dentro de un mundo instituido. Lo mejor, ha sido dicho, porque se evitan los grandes relatos, la ideología y la fe capaces de mover montañas, relatos aún necesarios y recuperables en tantos aspectos, pero que tan a menudo han acabado dejando caer la montaña encima de alguien. Lo peor, el fatalismo posibilista que esto parece implicar y también, desde el punto de vista práctico, que es difícil mantener una tensión crítica sin objetivos claros y aun más difícil contagiar tan sutil entusiasmo.

\section{Arte, público, producción. Estética relacional y posproducción}

Tras las bellas metáforas del tercer paisaje, situemos ahora la noción de intersticio o margen en el punto de encuentro entre práctica artística y público, en lo que se viene llamando prácticas relacionales, formas artísticas de proceder que afectan muy directamente a una noción actualizada de arte público.

Las prácticas relacionales habrían supuesto un corte en los desarrollos artísticos característicos de la posmodernidad. Constituirían una suerte de reset, muy propio de la era cibernética, que permitiría identificar como específicamente contemporáneo el arte a partir de los años 90 . Un reinicio o tal vez más moderadamente, un nuevo arte- 
punto-algo, al modo de las actualizaciones de software, mediante el cual, sin negar las etapas crítica (años 60 y 70) y posmoderna (años 80 ), incluso asumiendo valores del proyecto moderno e ilustrado, se constata que lo contemporáneo en arte no puede explicarse ya desde el aparato crítico que sirvió de sustento a aquellas prácticas relativamente recientes. Habría que repensar la propia situación de los artistas y del público en relación al nuevo ámbito de globalización e instantaneidad comunicativa que se afirma vertiginosamente desde los años 90 del pasado siglo.

Bourriaud procede a este análisis en su libro cuasi manifiesto Estética relacional (2001), sirviéndose de su experiencia como crítico y gestor cultural -puso en pie y dirigió el Palais de Tokio de París entre 2002 y 2005, uno de los proyectos artísticoinstitucionales europeos más originales durante aquellos años- y lo hace de forma muy aplicada, sirviéndose de una serie de artistas, según él, referentes del cambio constatado. Encuentra como factor común en ellos y auténtica marca epocal del arte de estas dos últimas décadas, su voluntad de hacer bascular su praxis sobre los juegos de relación que la obra establece con el regardeur, con "el que mira" que no es exactamente el público ni el espectador, términos connotados de pasividad. Así, la forma relacional se concreta en dispositivos de participación ("invitaciones, audiciones, encuentros, espacios de convivencia, inauguraciones"), de interactividad y de completamiento activo por parte del que mira (Fig. 2):

Si observamos las prácticas artísticas contemporáneas, más que las "formas", deberíamos hablar de las "formaciones". Lo opuesto a un objeto cerrado sobre sí mismo por un estilo o una firma. El arte actual muestra que solo hay forma en el encuentro, en la relación dinámica que mantiene una propuesta artística con otras formaciones, artísticas o no. (...) La esencia de la práctica artística residiría así en la invención de relaciones entre sujetos; cada obra de arte en particular sería la propuesta para habitar un mundo en común. (Bourriaud, 2008, pp. 22-23).

Indudablemente todo esto nos sitúa en el campo de lo que podríamos entender por arte público en el sentido de un arte con y para el público, pero, por otra parte, lo cierto es que casi todos los ejemplos aducidos desde la estética relacional son de artistas que trabajan generalmente en los espacios instituidos del arte. En las distintas clases de caja blanca. Tal vez por ello, Bourriaud se ocupa extensamente de dotar de solvencia ética a su comisariado artístico, siempre institucional y a menudo espectacular. Preserva a tal fin algunos aspectos del proyecto ilustrado moderno, postulando el alto valor político y el potencial emancipador de las prácticas relacionales y la necesidad de mantener un cordón umbilical con la modernidad: "¿Cómo un arte centrado en la producción de tales modos de convivencia puede volver a lanzar, completándolo, el proyecto moderno de emancipación?", se pregunta. La respuesta estaría, efectivamente, en la vinculación de relacional con político: "El arte contemporáneo desarrolla efectivamente un proyecto político cuando se esfuerza en abarcar la esfera relacional, problematizándola." (2008, pp. 15-16). 


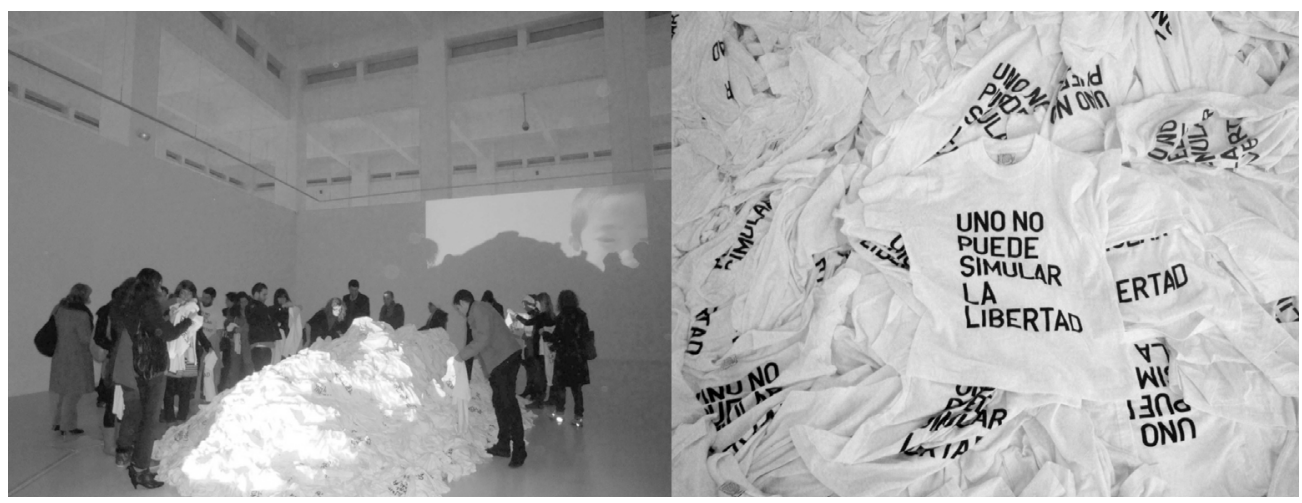

Figura 2. Rirkrit Tiravanija, Una larga marcha. Instalación en CAC Málaga 2009.

Aunque la crítica posmoderna a la ideología está muy presente en el análisis relacional de los términos que vinculan hoy arte y sociedad, es muy sintomática la reactivación del momento vanguardista, tanto como del ilustrado; en tal reconsideración de estas nociones modernas se percibe la necesidad reconstruir, aunque en términos diversos, puentes volados en la posmodernidad. "El arte [de las vanguardias] tenía que preparar o anunciar un mundo futuro: hoy modela universos posibles" (Bourriaud, 2008, p. 11). Hay pues aún utopías, pero no aquellas enajenadas del mundo, bombas de relojería cargadas de idealismo e ideología, sino las que tienen voluntad de permanecer en él con prácticas de desplazamiento más que de enfrentamiento: habría llegado el momento de la utopía de la proximidad, de la Dolce utopia, propuesta por el artista Mauricio Cattelan, pues frente al arte de la modernidad "el arte ya no busca representar utopías, sino construir espacios concretos" (2008, p. 55). La teoría relacional, no en vano tratada como estética, quiere actuar directamente sobre el mundo del arte y lo hace de un modo muy aplicado y práctico. Trabaja más con constataciones acerca de los cambios sociales generados por los nuevos modos de relación y conocimiento surgidos con la globalización comunicativa, que con argumentaciones en profundidad sobre los conceptos que maneja. Así ocurre con la Ilustración y sus correlatos de modernidad y emancipación: no hay un análisis crítico al respecto y sólo se manejan interpretaciones prestablecidas sobre estos conceptos. Lo interesante de esta suavizada apropiación de la modernidad no es tanto el discurso, sin duda demasiado simplificado, como la necesidad que manifiesta de mantener la genealogía moderna como argumento de autoridad frente al desprestigio posmodernista, con cuyas derivas más espectaculares y de instituida corrección política podrían, y muy fácilmente, confundirse a menudo las prácticas artísticas relacionales. 
La Estética relacional surge ya desde su enunciación, de la necesidad de releer las nuevas actitudes artísticas y sociales en relación a la eclosión de las diversas manifestaciones de la globalización, muy particularmente de Internet. Posteriormente y como su correlato, Bourriaud acuña el interesante y algo canalla término de "posproducción" que dará título al libro homónimo Posproducción (2003). Con él se aproxima a las nuevas formas de producción surgidas o relacionadas con la red, dando argumentos más precisos en cuanto a la cualidad y generalización del modus operandi del arte relacional. La posproducción consistiría en la práctica de generar "protocolos de uso para los modelos de representación y las estructuras formales existentes" (Bourriaud, 2009, p.14). Pasó la época de la creación, del autor como generador de imágenes nuevas, el artista es ahora un navegante que recoge códigos de la cultura y formalizaciones de la vida común, que usa el patrimonio entero del arte culto y popular, actual y pasado, y lo reelabora significativamente. La posproducción sería entonces la operación relacional por excelencia pues todo el material con que trabaja pertenece a un imaginario y unas formas compartidas, conocidas y no arcanamente misteriosas. A través de ellas el arte puede proponer nuevas apropiaciones y formas de habitar el mundo compartidas con "el que ve". El artista pero también el receptor de sus propuestas, reactivan mediante estos dispositivos lo ya conocido hacia nuevos significados. En palabras de la artista Dominique Gonzalez-Foerster (Fig. 3): "lo importante es introducir una especie de igualdad, suponer que entre yo -que estoy en el origen de un dispositivo, de un sistema- y el otro, unas mismas capacidades, la posibilidad de una idéntica relación, [que] le permiten organizar su propia historia como respuesta a la que acaba de ver, con sus propias referencias" (citado en Bourriaud, 2009, p 16).

Pero, al actuar así, el arte no hace nada que no hagan con mucha naturalidad otros agentes de la cultura actual: "La práctica del DJ, la actividad de un internauta y la de los artistas de la posproducción implican una figura similar del saber, que se caracteriza por la invención de itinerarios a través de la cultura. Los tres son semionautas que antes que nada producen recorridos entre signos" (Bourriaud, 2009, p. 14). La analogía entre los modos de proceder basados en el sample, propios de las sesiones musicales propuestas por el DJ, y los del arte contemporáneo son constantes e ilustran bien esta propuesta de posproducción, de reelaboración ad infinitum, como forma actual de la cultura. Es también, indudablemente, un revulsivo calculado que se lanza sobre el cerrado mundo del arte contemporáneo y la alta cultura: "Su set [del DJ] se emparenta con una exposición de objetos que M. Duchamp hubiese llamado 'ready-mades asistidos': productos más o menos 'modificados' cuyo encadenamiento produce una duración específica... el deejaying implica una cultura del uso de las formas que vincula entre sí rap, la música tecno y todos sus derivados posteriores" $(2009$, p. 43). 


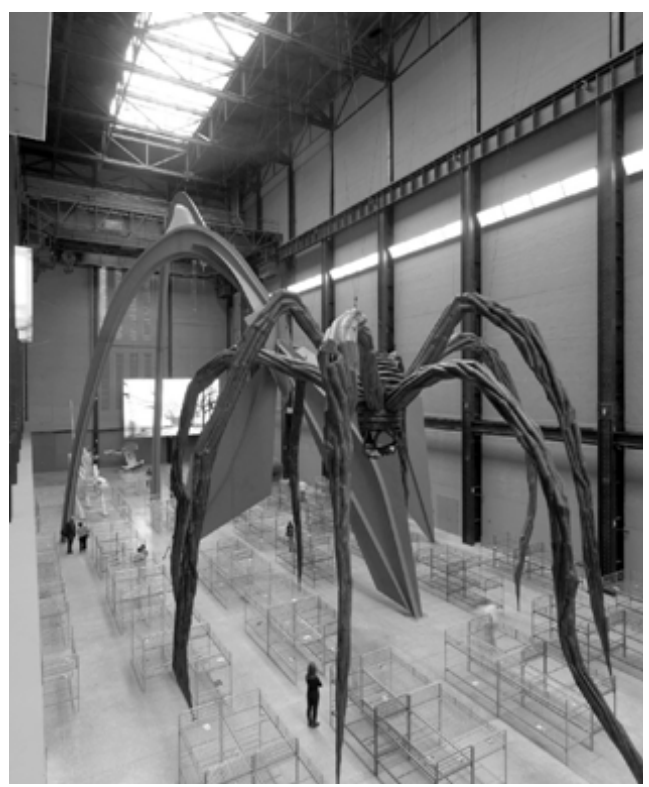

Figura 3. Dominique Gonzalez-Foerster, TH.2058. Tate Modern, Londres 2008.

Pasando por encima de la interesada interpretación del dispositivo duchampiano, esta ejemplificación mediante el deejaying nos sitúa de lleno en el proceder posproductivo e ilustra una de las nociones más interesantes de entre las propuestas por Bourriaud: lo que el autor acaba denominando "comunismo formal". Tal término hace alusión a la circulación y mezcla constante e interminable de las formas de la cultura y el arte, así como a su permanente disponibilidad más allá de los parámetros con que un día el autor las concibiera. En tal panorama, la forma acaba definiéndose por su disponibilidad para el uso, su realización y su éxito está en función de la apropiación que otros hagan de ella, en su capacidad de ser reutilizada. Esto convierte al arte en un "agente activo, una partitura, un escenario" que genera comportamientos en una comunicación activa, desmontando la dualidad mercancía-consumidor.

En esta nueva forma de cultura que podríamos calificar de cultura del uso o cultura de la actividad, la obra de arte funciona pues como la terminación temporaria de una red de elementos interconectados, como relato que continuaría y reinterpretaría los relatos anteriores. Cada exposición contiene el resumen de la otra; cada obra puede ser insertada en diferentes programas y servir para múltiples escenarios. Ya no es una terminal, sino un momento en la cadena infinita de las contribuciones. (Bourriaud, 2009, pp. 16-17).

Lo interesante de la propuesta relacional y su metodología productiva de reciclaje es su análisis de la situación tras la eclosión de Internet y la globalización de redes y contenidos. Sin duda, muchas de estas actitudes son familiares para los nativos di- 
gitales: es el nuevo público para quien lo relacional y posproductivo es un horizonte natural. Mucho más discutible es su suposición de constituir la vía apropiada para algo así como un arte de vanguardia de hoy. Priorizar el flujo sobre los contenidos es problemático. Lo es incluso cuando ese flujo trae consecuencias ansiadas desde las vanguardias y posvanguardias, como una definitiva confusión entre alta y baja cultura, entre productor y receptor, entre mercancía y consumo. Centrar el valor y contenido del arte en su capacidad para generar dispositivos relacionales es dejar de lado los aspectos más complejos y los más personales de una obra o un artista. Los aspectos que, precisamente por ser los menos intercambiables, no suelen tener esa capacidad transitiva, surf, que les constituiría en sampler disponible. Piénsese en artistas comentados dentro del contexto relacional por el propio Bourriaud: Hirschhorn, Sierra, Orozco... Indudablemente pueden ser leídos en términos relacionales y esto ya justifica valorar el brillante análisis relacional y posproductivo, pero es también muy evidente que sus poderosas construcciones artísticas no se dejan resolver en manejables sampler. Y menos aun la potencia pública y política de sus propuestas.

Se insiste, pues, en el propio dispositivo que pone en funcionamiento lo relacional por encima de los contenidos. Pero, si el artista ha de generar únicamente modelos de relación evitando la creación autónoma en favor de los objetos previamente compartidos de la cultura para así propiciar "el intercambio interhumano", entonces la cuestión de los contenidos críticos del arte, incluso de los contenidos sin más, quedará muy relegada a favor de una autoreferecialidad incesante y sin cortes de la cultura existente: tautología y complacencia parecen inevitables. Tal vez la crítica más severa que pueda dirigirse al entusiasmo de la teoría relacional proceda del carácter en definitiva afirmativo de su acción y, en mucha mayor medida, de su concepto de posproducción con el que Bourriaud parece olvidar los propósitos críticos-ilustrados y vanguardistas- expresados por él mismo anteriormente. Es evidente que el valor de uso de algo destinado a una constante reutilización e intercambio devendrá valor de cambio: la relación deviene transacción. "En esto consiste, afirma Eric Alliez, la esquizofrenia de la estética relacional que, en los nuevos universales de la comunicación, pretende conferir a sus efectos surf una función de democratización alternativa... Lejos de liberar de su reificación económica 'el intercambio interhumano' 'en los intersticios de las formas sociales existentes', ella pilotea nuevos criterios de mercantilización y de gestión participativa de la vida, los cuales están presentes en el sesgo de esos dispositivos de exposición que ponen en escena la extensión intensiva de la "cultura de la interactividad"' (2006, p. 180).

\section{Distanciamiento estético y disenso político}

Pero con todo, la teoría relacional ha tenido la virtud de identificar procedimientos y dispositivos que, aun sin ser ciertamente los únicos posibles, caracterizan bien el proceder de buena parte del arte actual, aquel que sitúa al público en el centro de la acción del artista. Y siendo esto una premisa del Arte público -buscar nuevos modos y dispositivos de encuentro y diálogo con el público- parece clara la pertinencia del análisis relacional al tratar este modo de arte. Sin embargo, la trabazón política del discurso de la Estética relacional parece escasa y es en cualquier caso discutible, pues 
el hecho relacional, si bien sitúa el arte entre lo social, no implica automáticamente lo político. Convendrá entonces, de cara a un arte público verdaderamente intersticial y actuante, complementar la efectiva metodología comunicativa relacional con otros discursos más específicos acerca del arte y lo político que suplan sus carencias en este aspecto, sustituyendo complacencia surf por negatividad crítica. Consideremos pues a continuación otros puntos de vista acerca de la praxis artística plenamente centrados en su dimensión política, discursos alternativos y en muchos aspectos francamente opuestos al relacional, pero igualmente actuales y relevantes para una reconsideración del Arte público como arte político.

Hay que comenzar, como anunciaba antes, por definir, aunque escuetamente, qué pueda ser lo político y en que acepción es aquí considerado. Puede, tal vez, consensuarse que lo político es la actividad que reconfigura marcos de relación frente al "orden natural" de lo establecido, actividad que puede rescatar a individuos y grupos del lugar asignado y reconfigurar para ellos otra enunciación colectiva "que dibuja de nuevo el espacio de las cosas comunes", en palabras de Jacques Rancière. Pero lo político implica relaciones de antagonismo y resoluciones de consenso. Según Mieke Bal, que utiliza la diferenciación propuesta por Chantal Mouffe, frente a la política, que sería "la organización que resuelve el conflicto; lo político es donde el conflicto ocurre. Sin embargo, es en virtud de lo político que la vida social es posible. Puede prosperar, estar viva, y también ser peligrosa" (2010, p. 42). Lo político es entonces un territorio dialéctico donde el conflicto ensaya continuas resoluciones expuestas a su vez de inmediato al disenso; la tradición tiende a instituir consensos que inevitablemente devendrán abusivos, lo político, al igual que el arte, fuerza situaciones abiertas, reflexionantes.

El arte, que de no querido es político, si quiere serlo con efectividad y quiere actuar, debería entonces incidir en lo político, no en la política, indagar en el conflicto no en sus supuestas soluciones (verdades); debería propiciar el disenso y movilidad que la política -la "policía" según Rancière- como institución tiende a fijar. El origen de estas reflexiones está en el anatema lanzado por Adorno a la poesía, al arte, con su Después de Auschwitz y el debate que originó acerca del paradójico funcionamiento de la imagen o del mensaje cuando muestra el horror, o simplemente lo que con su mostrar quiere denunciar. Efectivamente, la imagen mueve a la empatía y ello al mismo tiempo que contribuye a la estetización del mal que muestra. La literalidad en el mostrar no activa verdaderamente resortes críticos, por el contrario, inmuniza imperceptiblemente contra ellos. Es hoy algo bien conocido. Bertolt Brech, referente siempre de estas discusiones, sabía que la empatía del espectador con el contenido explícitamente político que se le mostraba, debía ser puntual y tajantemente interrumpida con lo extraño, con el enigma, que es justamente lo que le ha de obligar a construir otra crítica, a tomar decisiones. A dejar, en definitiva, de ser espectador. El choque estético de la interrupción brechiana, y no tanto el contenido literalmente político, es la condición para agenciar el discurso que el arte vehicula en términos de pensamiento, de acción y de emancipación. 


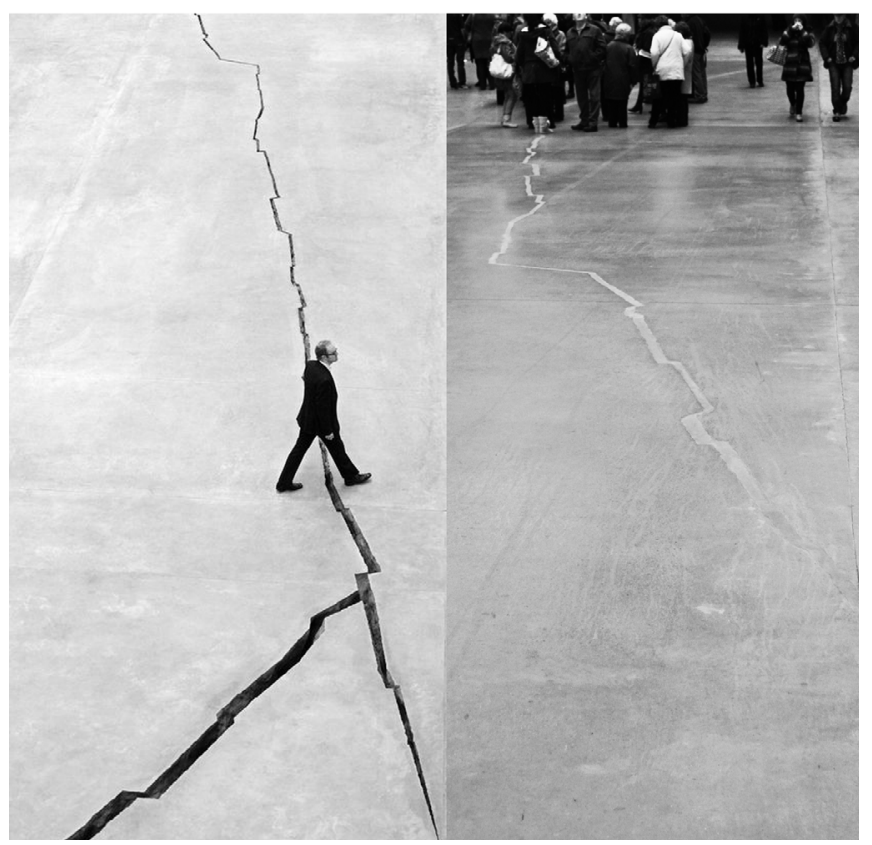

Figura 4. Doris Salcedo, Shibboleth, Tate Modern, Londres 2007. A la derecha, estado en 2012.

Entonces, ¿cómo hace efectiva el arte su inevitable dimensión política abriendo esos intersticios o terceros paisajes de los se hablaba al comienzo? Y, ¿cómo hacerlo hoy, sin alimentar su propia reificación en el insaciable escenario global? Mieke Bal propone a la artista colombiana Doris Salcedo (Fig. 4) como ejemplo de un arte de lo político porque, sin recurrir a representaciones manifiestas, solo con el silencio metafórico y connotado de sus obras, logra integrar y activar performativamente las experiencias compartidas de una comunidad, fomentando el juicio acerca del conflicto (la situación de violencia en la Colombia de hace algunos años). El espectador tiene que experimentar, que estar dispuesto y, ciertamente, la obra no tiene ninguna garantía de cumplirse, pero si lo logra, entonces su acción es política en el sentido de que activa el conflicto, no lo adormece. El arte político no sería, pues, el que habla abiertamente de política ni el que en función de sus contenidos explícitos está patrocinado por el estado o, por el contrario, censurado por él. Tampoco lo es el que desde la asepsia de la institución arte hace sus declaraciones: su significado será político pero no actúa políticamente como puede hacerlo el arte. Mieke Bal cree que el límite donde el arte es capaz de situar lo político está justo donde Wittgenstein cierra su Tractatus: "de lo que no se puede hablar, hay que callar". Y ocurre que el arte aún puede hablar donde ni el periodismo ni la filosofía hallan ya propiedad para ello.

A ese silencio, ajeno a la inmediatez representacional, mediante el cual, no obstante, el arte es capaz de activar lo innombrable, incluso la imagen intolerable, Jacques Rancière lo llama "eficacia estética". "Un arte crítico es un arte que sabe que su efecto político pasa por la distancia estética. Sabe que ese efecto no puede ser garantizado, 
que conlleva siempre una parte indecidible" (2010, p. 85). La eficacia estética procede de su capacidad para constituirse en ruptura que desconecta saberes y experiencias previos, abriendo el campo de un disenso, de un margen antes no conocido y situado fuera de la continuidad de las causas y efectos previstos; un campo reflexionante. Pero, como afirmaba Mieke Bal, en el corazón de lo político está también el disenso: política no es esencialmente el ejercicio del poder sino el territorio del conflicto y los constantes reequilibrios. El encuentro entre estética y política se daría, precisamente, en ese disenso y no en la continuidad: "si la experiencia estética entra en el terreno de la política, es porque ella también se define como experiencia de disenso, opuesta a la adaptación mimética o ética de las producciones artísticas con fines sociales" (Rancière, 2010, p. 64). El arte no es político cuando actúa linealmente respecto a los efectos buscados, cuando se empeña en anular toda distancia entre realidad y estética, porque entonces la capacidad de desconexión, de ruptura y disenso de la estética se anula, se disuelve en los efectos ya previstos y nada aporta al comentario político más allá de lo periodístico o lo moralizante. Por otra parte, ¿a quién interesa o es capaz de convencer tal o cual mensaje crítico cuando es explícita y unívocamente expresado por una obra artística? A quien previamente lo compartía. Tan escasa efectividad reviste esa clase de arte mal llamado político.

Vuelve, pues, a hablarse de un conocimiento sensible, de una estética que no es ya desde luego la del gusto de sus orígenes, sino que se propone como condición, o al menos propedéutica, de emancipación y detonante de acción. Como indicaba, la Ilustración siempre ha permanecido..., aunque tal como defiende Habermas, como proyecto incumplido; y la teoría crítica, con su correlato estético adorniano, no deja de ser una de sus manifestaciones en unos u otros aspectos aún actualizable. Su crítica a la industria cultural, cuando hoy este término se usa afirmativamente con la mayor naturalidad incluso desde el propio ámbito artístico, es pertinente para un arte construido sobre la conciencia del propio estatus cultural y social; también lo es la defensa de una reserva de autonomía para el arte como condición de su acción estéticocrítica. Veíamos cómo la Estética relacional se dotaba de una genealogía moderna, vinculándose en cuanto a su dimensión política al proyecto ilustrado vehiculado por las utopías vanguardistas y cómo lo matizaba hasta desfigurarlo en utopías posibles; también, cómo la idea misma de estética, aun cuando recuperada tras largo tiempo desaparecida, perdía en ella su acepción fuerte, presente en el pensamiento moderno y la noción de autonomía, deviniendo rápido fluir negociable de propuestas heterogéneas y reciclables. Ante tales posturas, en definitiva profundamente posmodernas, será útil reparar -una vez más- en ese inconcluso proyecto ilustrado al que el propio Bourriaud decía adscribirse. No se trata ciertamente de pensar un arte como el solicitado por Adorno, solo actuante desde una separación radical del mundo de la vida, sino simplemente de devolverle parte de la responsabilidad que asumió con la modernidad. No la del arte por el arte sino otra que implica política y estética.

Jacques Rancière, siempre interesado por tal binomio, se sustrae de los análisis marxistas y su imposición especializada de la ideología correcta, recuperando el pensamiento surgido en el seno de los propios movimientos obreros de la época previa al socialismo científico. De tal contexto extrae una imagen potente y expresiva al tiempo que clarificadora, con la que vale la pena ilustrar estas reflexiones acerca de 
la carga política inherente a la estética, su capacidad para expandir el límite asignado por lo establecido a las personas. Durante la revolución de 1848 en Francia, un diario revolucionario obrero publicó la descripción de la jornada de trabajo de un ebanista que tiene por encargo entarimar una habitación:

Creyéndose en casa, aunque no ha terminado la habitación que está entarimando, aprecia la disposición; si la ventana da al jardín o domina un horizonte pintoresco, por un momento detiene sus brazos y planea mentalmente hacia la espaciosa perspectiva para gozar mejor de ella que los poseedores de las habitaciones vecinas. (Rancière, 2010, p. $65)$.

La mirada del ebanista libre y distanciada del lugar que le ha sido asignado -que es el de la fuerza de sus brazos- supone, según Rancière, un disenso, una interrupción respecto a lo que la política le tiene destinado. "Para los dominados, la cuestión no ha sido nunca tomar conciencia de los mecanismos de la dominación, sino crearse un cuerpo consagrado a otra cosa que no sea la dominación. No se trata, como nos indica el mismo carpintero, de adquirir un conocimiento de la situación, sino de 'pasiones' que sean inapropiadas para esa situación" (2010, pp. 65-66).

El arte (siempre público y siempre político) tiene que ver con esto, con las "pasiones inapropiadas" que perturban lo previsto y lo establecido para cada cual por la política y las estructuras culturales dadas. Son esas pasiones "indecibles" que hallan su dicción en el arte, las que abren márgenes de diversidad, terceros paisajes. Las que pueden generarse desde unas prácticas relacionales que resitúen constantemente el arte entre el público, pero no por el placer del puro fluir sino orientadas a la dislocación, dando el tiempo para una recepción colaborativa y reflexionante, abriendo así espacios de emancipación. Pasiones inapropiadas que son también las que, dentro de la práctica artística, resuelven toda contradicción entre estética y política.

\section{Referencias}

Adorno, T. \& Horkheimer, M. (2007). Dialéctica de la Ilustración (1944). Madrid: Akal.

Alliez, E. (2006). Capitalismo, esquizofrenia y consenso de la Estética relacional. Nómadas, 25. Bogotá: Universidad Central. Recuperado de http://redalyc.uaemex. $\mathrm{mx} / \mathrm{src} / \mathrm{inicio} /$ ArtPdfRed.jsp?iCve $=105115224016$

Bal, M. (2010). Arte para lo Político. Estudios visuales, 7. Murcia: CENDEAC. Recuperado de http://www.estudiosvisuales.net/revista/pdf/num7/03 bal.pdf Bourriaud, N. (2008). Estética relacional (2001). Buenos Aires: Adriana Hidalgo. Bourriaud, N. (2009). Postproducción (2003). Buenos Aires: Adriana Hidalgo. Bürger P. (2000). Teoría de la vanguardia (1974). Barcelona: Península.

Clément, G. (2007). Manifiesto del Tercer paisaje (2004). Barcelona: Gustavo Gili. Rancière, J. (2010). El espectador emancipado (2008). Castellón: Ellago Ensayo. 